\title{
Simulation-Supported Verification of Methods for Controlling Disassembly Lines
}

\author{
Jan Hrdina ${ }^{1}$ and Gert Zülch ${ }^{2(\bowtie)}$ \\ ${ }^{1}$ Conti Temic Microelectronic GmbH, 90411 Nuremberg, Germany \\ jan.hrdina@continental-corporation.com \\ 2 ifab-Institute of Human and Industrial Engineering, \\ Karlsruhe Institute of Technology, 76131 Karlsruhe, Germany \\ gert.zuelch@gefora-beratung.de
}

\begin{abstract}
In order to follow the principles of sustainability disassembly of end-of-life products is necessary for the re-use of their parts and sub-assemblies. In contrast to production control of assembly systems, disassembly lines feature some peculiarities: used components can be proven to be non-detachable or even missing, so that with increasing disassembling progress the desired components can no longer be gained, and there is a threat that the stations and workers assigned to them would remain idle. This paper describes a procedure for controlling division of labor-based lines, which follow the flow principle and are tailored to the specific features of disassembly control. It aims at maximizing the disassembly proceeds and the utilization of the disassembly stations, but it also considers the uniformity of their utilization. Thereby future disassembly lines can be operated in a way that efficiently counters the increasing volume of end-of-life products to be disassembled. The effectiveness of the procedure is verified by means of a simulation-supported application study.
\end{abstract}

Keywords: Disassembly line $\cdot$ Flow principle $\cdot$ Disassembly control $\cdot$ Staff deployment $\cdot$ Simulation

\section{Requirements for an Economical Disassembly Process}

Due to legal requirements, in particular due to the European Waste Framework Directive 2008/98/EG [1] and the principle of producer responsibility that goes along with the basis of changing values towards greater environmental awareness ([2], p. 7), an increase in the amount of end-of-life products to be disassembled can be expected in the future. At the same time disassembly processes are characterized by generally low value creation compared to industrial production. Disassembly inefficient operations often prevail, exacerbating the situation further. Moreover, disassembly is often characterized by poor working conditions (e.g. noise, dirt, muscular stress etc.).

Therefore it is firstly necessary to reduce disassembly costs through systematic planning and control of the related processes. Secondly, the cost-effectiveness of disassembling improves when it is of an increasingly industrial character. However, to a greater extent automation is only technically and economically feasible with special end-of-life products. Nevertheless, a combination of manual operations with automated 
sub-processes - featuring so-called hybrid and flexible automated systems - is seen as especially economical (e.g. [3], p. 290).

During disassembly, however, due to the uncertainty with respect to the properties of the end-of-life products, the operations to be performed are not fixed and therefore not deterministic (e.g. [4], p. 374). The selected disassembly methods must be chosen depending on the condition of the individual end-of-life product, from which the necessary processing times can possibly then be derived [5].

The scope of the used parts or sub-assemblies to be disassembled, i.e. the degree of disassembly, is also not necessarily specified. Instead, depending on the respective state of each end-of-life product this must be re-determined from an economic point of view ([6], p. 31). For this reason it is logical that the degree of disassembly should not be equated with the degree of assembly, because it is operation-based, not product-based.

\section{State of the Art for Control of Disassembly Systems}

According to Zülch ([7], p. 56) there are basically three possible measures by which the processes of a given production order program can be controlled appropriately. These are: changing the order size (for example, by combining orders $\mathrm{A}$ and $\mathrm{B}$ ), changing of order sequences (bringing forward order B to before order A) as well as the initialization logic (e.g. splitting an operation or order). In principle, these control measures have been developed for parts manufacture and assembly.

However, such control measures are only conditionally suitable for disassembly orders, since they do not account sufficiently for their specific characteristics. In division of labor-based systems such as disassembly lines, the control problem is complicated by the diversity of end-of-life product types and by the various usage states of the individual product. The latter in particular must be considered during disassembly control. Especially in manual systems compared to conventional production systems advanced or more detailed control measures are needed in manual systems in order to achieve efficient processes for disassembly.

As early as 1996 Geiger et al. [8] recognized that disassembly must be reactively controlled. The reason for this is that extraction of certain end-of-life components depends on the success of the disassembly of its previous components. Moreover, the state of these components determines the likelihood of successful disassembly (cf. ibid., p. 49).

Many literature sources regard the assignment of disassembly operations to stations, thus regarding the planning problem of line balancing (e.g. [9]). As a control task, the planning of the order sequence is considered. Some authors try to solve this problem analytically using methods of operations research $[10,11]$. But these procedures solve only problems without any disassembly-typical disturbances.

Lee and Bailey-Van Kuren [12] investigate disassembly strategies with the help of the simulation using two end-of-life products as examples. The strategies are material-oriented and are carried out in robotic cells. Their contribution focuses on the mutual blocking of components; other disassembling difficulties are not considered.

As part of the planning of a hybrid disassembly system, Kim et al. [13] developed reactive control measures. Their application, however, also involves a robotic 
automated disassembly system, but not the manual systems considered in this paper. There is no evidence of the effectiveness of the developed method, as it is the case here using simulation. In a further study of this procedure, Kim et al. [14] use the simulation of another hybrid system to select from the possibilities of alternative disassembly operations a feasible one. Whether this procedure is also valid for an entire order program, as it is the case in our paper, is not checked with the aid of the simulation.

As a result, the control concepts proposed in the literature do not take into account disassembly specific difficulties, or if so then only partially - that is if such a concept considering a disassembly order program consisting of different end-of-life products exists at all. A dynamic, reactive control that takes into account available human and technical resources has not been carried out with any of the previously presented methods.

\section{Development of a Novel Disassembly Control Procedure}

In order to respond to difficulties or disturbances during disassembly it is not enough to manage these short-term changes to the order sequence with so-called re- sequencing or re-scheduling measures. Rather, the novel disassembly control procedure must be capable of much more, namely a re-configuration of the existing flow principle. In the sense of reactive control short-term scheduling should be feasible (e.g. a re-assignment of individual disassembly operations to line stations). Moreover, the control procedure must allow for a re-distribution of operations in conjunction with an adaptive-dynamic work plan ([6], p. 29). Consequently, what is sought is a short-term work schedule taking the given additional constraints into account (e.g. limited resources, cycle time) and as much compliance with the objectives as possible (e.g. high utilization of disassembly stations).

The following assumptions determine the initial situation that is the basis for the novel disassembly control procedure: It is assumed that there is a pre-existing balanced disassembly line with one worker at each station and an order program whose end-of-life products initially shall be disassembled in a pre-defined sequence. This order program can consist of different variants of an end-of-life product type with individual product states.

In terms of economics, the objective of the procedure developed here is, on the one hand, to ensure a high and most uniform utilization of the existing disassembly stations. On the other hand, the proceeds or contribution margin of the initialized disassembly order program for a defined planning period is to be maximized.

In the following, control measures are discussed that can react to disassembly specific difficulties or disturbances in an adaptive-dynamic manner (cf. also e.g. [15, 16]). In this approach, priority is given to a manual disassembly system ([17], p. 101):

- Variation of disassembly operation sequences

- Variation of disassembly operations

- Variation of disassembly tools 
- Variation of the disassembly order sequence

- Variation of the disassembly depth

- Re-assignment of disassembly operations to stations.

Figure 1 illustrates the general flow of the newly developed disassembly control procedure: For each disassembly station the remaining time for the current order program is determined. Taking into account the available control measures the one is then selected, that on the one hand maximizes the disassembly proceeds and on the other hand maximizes the utilization of the disassembly stations, but also considering the uniformity of their utilization.

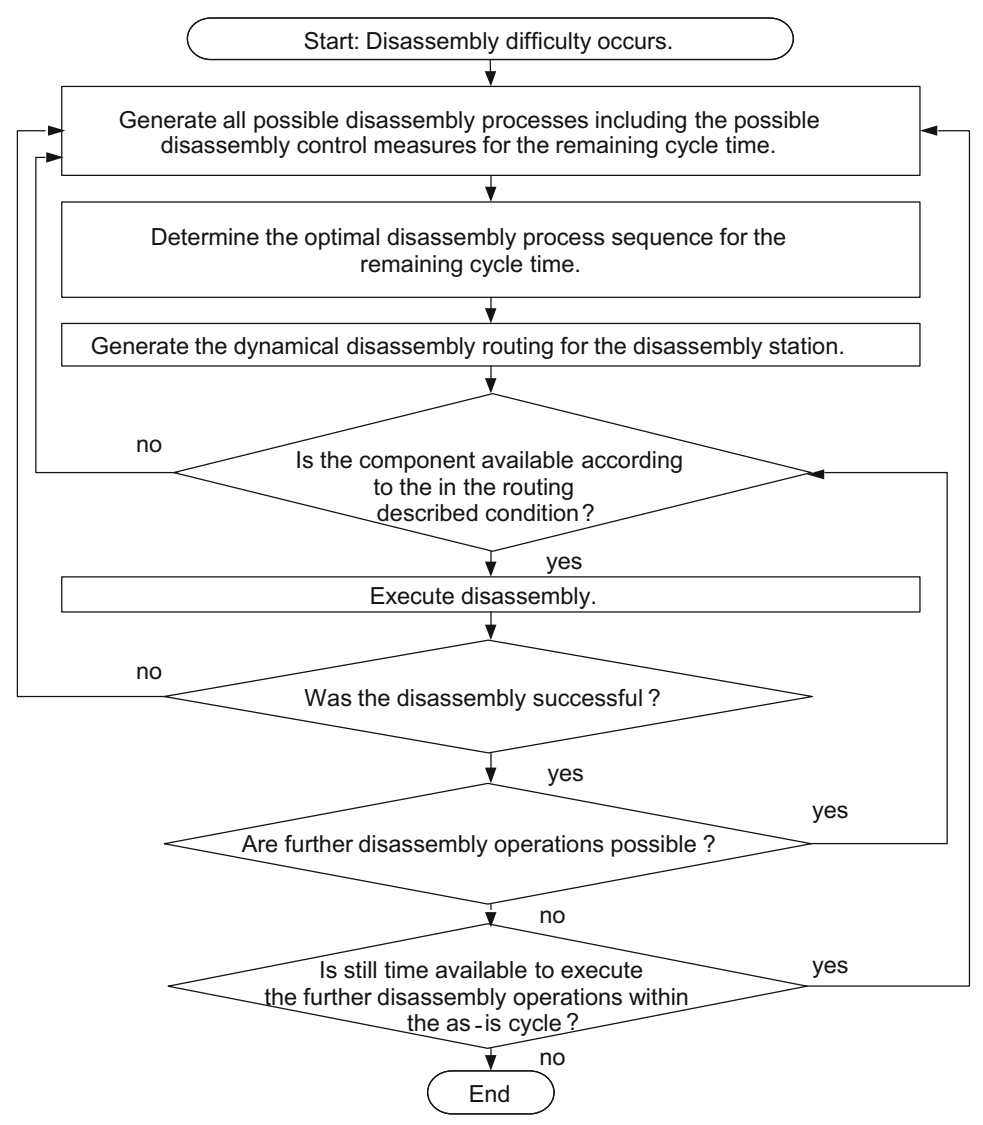

Fig. 1. Disassembly control procedure by re-assignment and operation-related measures for a disassembly station (according to [16], p. 404) 


\section{Verification of the Effectiveness of Developed Control Measures}

\subsection{Aim and Scope of the Study}

Below the effectiveness of the developed algorithm and control measures is shown with the aid of the simulation using an application study: In a disassembly line an order program that consists of three different variants of an end-of-life product is executed in a defined order period. The end-of-life products are disassembled at four stations in a line with one employee at each station.

Three variants of an end-of-life product type with beta distributed activity times with respect to the applicable tools are available as well as the associated potential proceeds. Furthermore, the feasibility probability, the damage probabilities and the probability of depreciation due to damage associated with the respective tool are considered. Of the examined different control scenarios, only two are presented here, the initial solution as well as the most favorable improvement solution.

The following scenarios were conducted with a simulation period of $8 \mathrm{~h}$. Included here were end-of-life products to be disassembled with the order sequence Variant A, Variant B, Variant C, Variant A etc. with the setting batch size 1.

The simulation results are shown in the following. The presented figures illustrate the Gantt chart representations, stating the workload of staff (and thus implicitly of stations). In addition, the tables contain the disassembly proceeds generated (shown here simply as 1 currency unit - CU - each per disassembly operation). To reduce the randomness of the results obtained, 10 simulation runs were carried out with different seeds for random numbers. Both, the respective results of the simulation runs as well as the average over all runs are listed.

\subsection{Situation of the Initial System}

The initial situation in modelled with the following assumptions: In the case of workflow disturbances, the workers select randomly a control measure or an alternative disassembly operation. The disassembly stations have an average workload of $83.0 \%$ (Fig. 2 and Table 1). Disassembly Station 4 is particularly poor with 77.2\%; Disassembly Station 1 on the other hand has already achieved relatively high workload at $89.4 \%$. The aim of the disassembly control procedure is to achieve high proceeds as well as a uniform utilization of all disassembly stations. In the initial situation, the difference between the busiest and least busy disassembly station is $12.2 \%$. The disassembly proceeds amount to $7,854 \mathrm{CU}$.

\subsection{Possible Control Improvements}

The improvement solution is run under the following assumptions: Through buffers, staff can access the operations of the previous disassembly stations, and thereby help each other during processing. Determination of the disassembly proceeds is achieved 


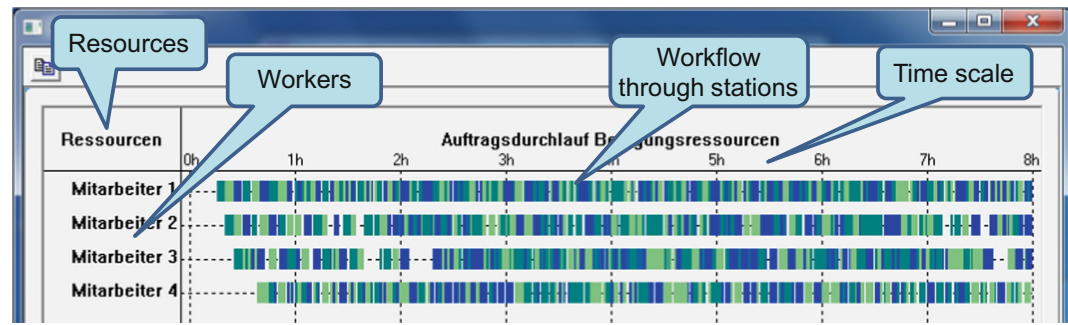

Fig. 2. Gantt chart representation of the initial situation (following [17], p. 146)

Table 1. Proceeds and utilization of the initial situation (cf. [17], p. 147)

\begin{tabular}{ccccccc}
\hline $\begin{array}{c}\text { Simulation } \\
\text { run }\end{array}$ & $\begin{array}{c}\text { Proceeds } \\
\text { in CU }\end{array}$ & $s=1$ & \multicolumn{3}{c}{ Workload in \% } & \multicolumn{2}{c}{ Average } \\
\hline 1 & 7.982 & 90,3 & 83,1 & $s=3$ & $s=3$ & $s$ \\
2 & 7.805 & 89,3 & 84,1 & 82,9 & 79,7 & 84,0 \\
3 & 7.810 & 89,6 & 80,5 & 77,2 & 75,2 & 82,7 \\
4 & 7.682 & 88,5 & 83,9 & 81,4 & 74,6 & 81,5 \\
5 & 8.010 & 89,9 & 84,8 & 85,4 & 77,4 & 82,0 \\
6 & 7.924 & 89,0 & 87,2 & 82,5 & 77,9 & 84,4 \\
7 & 7.718 & 89,0 & 82,5 & 82,6 & 74,7 & 82,2 \\
8 & 8.022 & 89,0 & 83,1 & 79,8 & 80,7 & 83,2 \\
9 & 7.982 & 89,1 & 84,7 & 85,0 & 77,5 & 84,1 \\
10 & 7.606 & 89,8 & 85,9 & 75,3 & 76,5 & 81,9 \\
\hline Average & 7.854 & 89,4 & 84,0 & 81,4 & 77,2 & 83,0 \\
\hline
\end{tabular}

by the developed control algorithm, whereby a re-assignment of disassembly operations to stations can be carried out if this is appropriate.

Thus, those disassembly operations are selected which promise the highest possible proceeds. Through a re-assignment of disassembly operations to stations in conjunction with the instruction which end-of-life product is to choose those alternatives that promise the highest proceeds, the following results can be obtained: The proceeds now achieve 8,411 CU. The difference between the busiest (91.6\%) and least busy disassembly station (82.4\%) stands at $9.2 \%$, while the average workload is $87.2 \%$ (Fig. 3 and Table 2).

\subsection{Conclusion of the Application Study}

With the help of the application study performed here, it has been demonstrated that the disassembly processes can be improved with the help of the developed control procedure. Although the disassembly line is already highly utilized in the initial situation, as the static workload across all disassembly stations shows with an average of $83.0 \%$, and relatively high disassembly proceeds, the system can still be improved. Through the use of the developed disassembly control procedure in the improvement solution, utilization of all disassembly stations can be further increased. The proceeds will improve by $557 \mathrm{CU}$ or $7.1 \%$. 


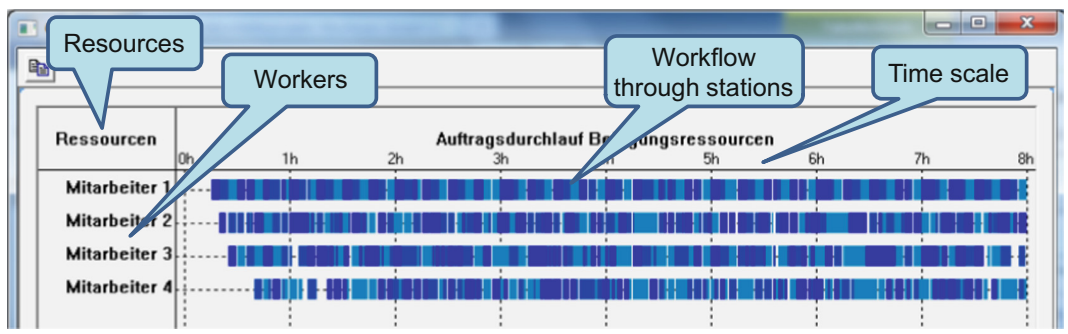

Fig. 3. Gantt chart illustration of the improvement solution (following [17], p. 151)

Table 2. Proceeds and utilization of the improvement solution (cf. [17], p. 151)

\begin{tabular}{|c|c|c|c|c|c|c|}
\hline \multirow{2}{*}{$\begin{array}{c}\text { Simulation } \\
\text { run }\end{array}$} & \multirow{2}{*}{$\begin{array}{c}\text { Proceeds } \\
\text { in } \mathrm{CU}\end{array}$} & \multicolumn{4}{|c|}{ Workload in \% } & \multirow{2}{*}{$\begin{array}{c}\text { Average } \\
s\end{array}$} \\
\hline & & $s=1$ & $s=2$ & $s=3$ & $s=3$ & \\
\hline 1 & 8.218 & 91,7 & 86,2 & 87,4 & 79,3 & 86,1 \\
\hline 2 & 8.233 & 91,0 & 87,5 & 88,5 & 83,2 & 87,6 \\
\hline 3 & 8.344 & 91,0 & 86,5 & 89,6 & 84,1 & 87,8 \\
\hline 4 & 8.667 & 92,2 & 85,1 & 88,9 & 81,4 & 86,9 \\
\hline 5 & 8.430 & 91,4 & 86,0 & 89,5 & 83,5 & 87,6 \\
\hline 6 & 8.487 & 90,4 & 85,5 & 89,6 & 81,0 & 86,6 \\
\hline 7 & 8.348 & 92,2 & 85,2 & 89,4 & 81,5 & 87,1 \\
\hline 8 & 8.460 & 91,0 & 86,2 & 87,5 & 83,5 & 87,0 \\
\hline 9 & 8.559 & 92,8 & 87,0 & 89,6 & 82,7 & 88.0 \\
\hline 10 & 8.369 & 92,2 & 85,0 & 86,9 & 83,4 & 86,9 \\
\hline Average & 8.411 & 91,6 & 86,0 & 88,7 & 82,4 & 87,2 \\
\hline
\end{tabular}

Thus, the effectiveness of the disassembly control procedure is verified. In particular, the combination of the developed control measures can improve processes for division of labor-based disassembly systems.

\section{Summary and Outlook}

In this paper, a reactive control procedure has been developed that allows division of labor based disassembly systems to be controlled so that an existing order program can be as economically performed as possible. For this purpose, adequate disassemblyspecific control measures have been developed and brought together in an overall concept. In addition, the effectiveness of the procedure has been demonstrated.

For further improvements of the developed control procedure, the control measures must be communicated to staff in an appropriate form. In order to respond to specific situations, interaction between staff and control management should be facilitated by means of staff communicating current disassembly difficulties or disturbances to a control management system (e.g. using an earlier approach suggested by Schiller [6], p. 231). Staff then receives new operating procedures for the purpose of an updated selection of the end-of-life products and their components to be disassembled, as well as an updated work plan. 


\section{References}

1. 2008/98/EC: Directive 2008/98/EC of the European Parliament and of the Council of 19 November 2008 on waste and repealing certain Directives (2008). http://eur-lex.europa.eu/ LexUriServ/LexUriServ.do?uri=OJ:L:2008:312:0003:0030:en:PDF. Accessed 21 Mar 2017

2. Huber, A.: Demontageplanung und -steuerung. Dissertation, Magdeburg University, Germany. Shaker, Aachen (2001)

3. Uhlmann, E., Friedrich, T., Harms, R., et al.: Hybrid disassembly system. In: Seliger, G. (ed.) Sustainability in Manufacturing, pp. 290-311. Springer, Heidelberg (2007)

4. Grochowski, D.E., Tang, Y.: A machine learning approach for optimal disassembly planning. Int. J. Comput. Integr. Manuf. 22(4), 374-383 (2009)

5. Heinz, K., Mönig, O., Schwarz, R., Zülch, G.: Zeitermittlung für die manuelle Demontage. REFA-Nachr. 55(4), 15-18 (2002)

6. Schiller, E.F.: Ein Beitrag zur adaptiv-dynamischen Arbeitsplanung in der Demontage. Dissertation, Karlsruhe University, Germany. Shaker, Aachen (1998)

7. Zülch, G.: The strategic control cube - a systematic approach to PPC-strategies. In: Eloranta, E. (ed.) Advances in Production Management Systems, pp. 53-62. North-Holland, Amsterdam (1991)

8. Geiger, D., Zussmann, E., Lenz, E.: Probabilistic reactive disassembly planning. Ann. CIRP 45(1), 49-52 (1996)

9. Paksoy, T., Güngör, A., Özceylan, E., Hancilar, A.: Mixed model disassembly line balancing problem with fuzzy goals. Int. J. Prod. Res. 51(20), 6082-6096 (2013)

10. Lambert, A.J.D., Gupta, S.M.: Methods for optimum and near optimum disassembly sequencing. Int. J. Prod. Res. 46(11), 2845-2865 (2008)

11. ElSayed, A., Kongar, E., Gupta, S.M.: A genetic algorithm approach to end-of-life disassembly sequencing for robotic disassembly. In: Proceedings of the 2010 Northeast Decision Sciences Institute Conference, 26-28 March, Alexandria, VA, pp. 402-408 (2010)

12. Lee, K.-M., Bailey-Van Kuren, M.M.: Modeling and supervisory control of a disassembly automation workcell based on blocking technology. IEEE Trans. Robot. Autom. 16(1), 67-77 (2007)

13. Kim, H.-J., Harms, R., Seliger, G.: Automatic control sequence generation for a hybrid disassembly system. IEEE Trans. Autom. Sci. Eng. 4(2), 194-205 (2007)

14. Kim, H.-J., Kernbaum, S., Seliger, G.: Emulation-based control of a disassembly system for LCD monitors. Int. J. Adv. Manuf. Technol. 40(3-4), 383-392 (2009)

15. Zülch, G., Hrdina, J., Schwarz, R.: Development of a computer aided procedure to control division of labour based disassembly systems. In: Mitsuishi, M., Ueda, K., Kimura, F. (eds.) Manufacturing Systems and Technologies for the New Frontier, pp. 217-220. Springer, London (2008). doi:10.1007/978-1-84800-267-8_44

16. Zülch, G., Hrdina, J.: Control of disassembly systems based on the division of labour by means of dynamically adapting routing plans. In: Dangelmaier, W., Blecken, A., Delius, R., Klöpfer, S. (eds.) IHNS 2010. LNBIP, vol. 46, pp. 396-407. Springer, Heidelberg (2010). doi:10.1007/978-3-642-12494-5_35

17. Hrdina, J.: Beitrag zur Steuerung von arbeitsteiligen Demontagesystemen. Dissertation, Karlsruhe Institute of Technology, Germany. Shaker, Aachen (2014) 